\title{
LA INTELIGENCIA ESTRATÉGICA DEL ESTADO NACIÓN EN LA ERA POS-COVID-19'
}

\author{
NATION-STATE STRATEGIC INTELLIGENCE IN THE POST-COVID-19 ERA
}

\begin{abstract}
Andrés Eduardo Fernández-Osorio
$\mathrm{PhD}$ en Derecho y Ciencia Política, Universidad de Barcelona, España. Magister en Estudios de Defensa, King's College London, Reino Unido. Magíster en Economía, Estado y Sociedad: Política y Seguridad, University College London, Reino Unido. Magíster en Relaciones Internacionales, Escuela Superior de Economía Moscú, Federación de Rusia. Magister en Seguridad y Defensa Nacionales, Escuela Superior de Guerra "General Rafael Reyes Prieto", Colombia. Investigador Asociado categorizado por Minciencias.

Orcid: https://orcid.org/0000-0003-0643-0258

E-mail: andres.fernandez@buzonejercito.mil.co
\end{abstract}

\section{Carlos Alberto Ardila Castro}

Estudiante del Doctorado en Educación, Universidad Internacional Iberoamericana, de México. Magíster en negocios y relaciones internacionales, Universidad Militar Nueva Granada, Colombia. Profesional en ciencias militares, Escuela Militar de Cadetes "General José María Córdova", Colombia. Investigador asociado categorizado por Minciencias. Jefe de investigación de la Escuela Superior de Guerra "General Rafael Reyes Prieto", Colombia. Docente investigador y líder del grupo de investigación Centro de Gravedad, de la Escuela Superior de Guerra "General Rafael Reyes Prieto".

Orcid: https://orcid.org/0000-0002-8774-6176

E-mail: carlos.ardila@esdegue.edu.co

\section{Jonnathan Jiménez Reina}

Candidato a doctor en Seguridad Internacional, Universidad Nacional de Educación a Distancia (UNED), España. Magíster en Seguridad y Defensa Nacionales, Escuela Superior de Guerra "General Rafael Reyes Prieto", Colombia. Profesional en Política y Relaciones Internacionales, Universidad Sergio Arboleda, Colombia. Investigador Asociado categorizado por Minciencias.

Orcid: https://orcid.org/0000-0001-9042-834X

E-mail: jonnathan.jimenez@esdegue.edu.co

Convidados

RESUMEN: La idoneidad de los Estado - Nación y sus instituciones son puestos a prueba en su accionar por los cambios en los escenarios de seguridad y defensa a nivel nacional e internacional. Por esta razón, es menestar dar respuesta a la siguiente pregunta: ¿De qué manera la gestión de conocimiento aporta a los procesos de la inteligencia estratégica en la era pos-COVID-19 en

\footnotetext{
${ }^{1}$ Artículo de reflexión resultado del proyecto de investigación "Nuevas Amenazas en el siglo XXI: Fronteras y Derechos Humanos - Fase II", vinculado al grupo de investigación "Centro de Gravedad", registrado bajo el código COL0104976 y categorizado en A1 por el Ministerio de Ciencia, Tecnología e Innovación de Colombia (Minciencias), adscrito y financiado por la Escuela Superior de Guerra "General Rafael Reyes Prieto", Colombia. Los puntos de vista y los resultados de este manuscrito pertenecen a los autores y no reflejan necesariamente el pensamiento institucional de la ESDEG o las Fuerzas Militares de Colombia.
}

Revista de Direito Brasileira | Florianópolis, SC | v. 28 | n. 11 | p.04-15 | Jan./Abr. 2021 
Colombia? La metodología empleada para la elaboración del presente documento es cualitativa, descriptiva y analítica, en el que se presenta un panorama particular para obtener un acercamiento general y comprensivo del aporte de la gestión del conocimiento ante los procesos de la inteligencia estratégica en la era pos-COVID-19 en Colombia desde una perspectiva de seguridad multidimensional. La gestión del conocimiento aporta a los procesos de inteligencia estratégica dinamismo, una mayor comprensión de la información y los posibles escenarios, y llevar a cabo un proceso más consciente y claro de aprendizaje con respecto a las nuevas amenazas y crisis.

Palabras clave: Seguridad Multidimensional. Inteligencia Estratégica. Gestión del Conocimiento. Proceso de aprendizaje. Crisis.

ABSTRACT: The suitability of the State - Nation and its institutions are put to the test in their actions by the changes in the security and defense scenarios at the national and international sphere. For this reason, it is necessary to answer the following question: In what way does knowledge management contribute to the processes of strategic intelligence in the post-COVID-19 era in Colombia? The methodology used for the preparation of this document is qualitative, descriptive and analytical, in which a particular panorama is presented to obtain a general and comprehensive approach of the contribution of knowledge management to strategic intelligence processes in the post- COVID-19 in Colombia from a multidimensional security perspective. Knowledge management brings dynamism to strategic intelligence processes, a greater understanding of the information and possible scenarios, and to carry out a more conscious and clear learning process with respect to new threats and crisis.

Keywords: Multidimensional Security. Strategic Intelligence. Knowledge Management. Learning process. Crisis.

SUMÁRIO: Introducción. 1 Antecedentes de gestión del conocimiento e inteligencia estratégica en Colombia. 2 Escenarios de amenaza que posee colombia en la era pos-covid.19. 3 Papel que posee la gestión de conocimiento en los procesos de inteligencia estratégica en la era pos-covid 19 en Colombia. Referencias.

\section{INTRODUCCIÓN}

El carácter cambiante de los escenarios de seguridad y defensa ponen a prueba la idoneidad de los Estado - Nación y sus instituciones, así como su capacidad de recolectar, procesar y emplear información de manera adecuada, ante diferentes fuentes de incertidumbre y situaciones de crisis que, históricamente, han complicado de forma vertiginosa los niveles estratégicos, operacionales y tácticos. Frente a ello, éstas se pueden asumir desde: a) una posición de falta de conocimiento; b) una posición de resiliencia; y c) una posición de conocimiento (Ballesteros 2016).

Así, considerando la pandemia del COVID-19, que para el mes de octubre de 2020 a nivel mundial presentó 37'423.660 de casos confirmados y 1'074.817 de muertes (Organizacion Mundial de la Salud 2020), se logra evidenciar la falta de previsión de los actores del Sistema Internacional para su manejo y tratamiento, y el surgimiento de nuevas oportunidades de la inteligencia estratégica en el escenario pos-Covid-19 en el mundo y especialmente en Colombia. El conocimiento es importante y, por su parte, la gestión de este permite comprender el contexto social, político y económico propicia la consecución de los objetivos nacionales, generar un nuevo conocimiento mediante la investigación y esfuerzos conjuntos e innovar (Ballesteros 2016). Además, se invita a aprender de las experiencias que han tenido los demás actores y a considerar sus mejores prácticas, los medios y los modos mejores empleados en el instante en que se presentó una crisis. La búsqueda de conocimiento y oportunidades de mejora intensifican el aprendizaje y 
propician espacios para reaccionar y tomar decisiones en momentos decisivos (Ardila, Jiménez y Cubides 2018).

Las tendencias pos-COVID-19 advierte que los cambios que se generarán y entenderán a partir de la seguridad multidimensional a nivel estatal son enormes, hay una metaconsciencia colectiva acerca de las prioridades, el consumo y el desenvolvimiento de los gobiernos a nivel nacional e internacional; una evolución en el concepto de seguridad, defensa y bienestar; un panorama económico-social, político y sanitario más amplio; una transformación en el concepto de responsabilidad corporativa y la manera en la que las compañías deciden llevar a cabo sus operaciones -remoto-; y una recuperación de redes de apoyo local. La adaptación que deben hacer los Estado-Nación ante las nuevas amenazas y nuevos escenarios de crisis deben ser considerados oportunidades para impactar positivamente el desenvolvimiento del país en el Sistema Internacional (Ardila, Jiménez \& Acosta 2019).

De esta manera, el presente artículo pretende dar respuesta a la siguiente pregunta: ¿De qué manera la gestión de conocimiento y su regulación aporta a los procesos de la inteligencia estratégica en la era pos-COVID-19 en Colombia? Con el fin de determinar el papel que posee la gestión de conocimiento en los procesos de inteligencia estratégica en la era pos-COVID 19 en Colombia. Por tanto, en un primer momento se examinarán los antecedentes de la gestión del conocimiento y la inteligencia estratégica en Colombia, en un segundo momento se identificarán los escenarios de amenaza que posee Colombia en la era pos-COVID 19 desde una perspectiva de Seguridad Multidimensional y determinará el papel que posee la gestión de conocimiento en los procesos de inteligencia estratégica en la era pos-COVID 19 en Colombia.

\section{ANTECEDENTES DE GESTIÓN DEL CONOCIMIENTO E INTELIGENCIA ESTRATÉGICA EN COLOMBIA}

En Colombia, la inteligencia estratégica no ha tenido un desarrollo importante. A diferencia de otros Estados que crearon agencias de inteligencia con el fin de advertir todas las amenazas contra la integridad de sus respectivas naciones, Colombia, debido al culto irrestricto hacia los tratados internacionales evitó que en Colombia no desarrolló la inteligencia estratégica (Esquivel 2019).

La inteligencia estratégica, entendida como "el intento de los dirigentes por conocer las amenazas potenciales e inminentes a nivel nacional o internacional y sacar ventaja de ellas" (Esquivel 2019, 380), tradicionalmente no tuvo un mayor desarrollo en el país. Hasta 1953, año en el que se crea la primera entidad administrativa enfocada hacia el desarrollo de actividades de inteligencia, no se puede hablar de que en Colombia existiera el concepto de inteligencia estratégica.

Como consecuencia de esto, Colombia sufrió hasta ese año alrededor de 34 sorpresas estratégicas que dan muestra del profundo descuido de la inteligencia estratégica por parte del Estado (Esquivel 2019). Este mismo autor señala que la Colombia republicana, en 1888, reorganizó sus fuerzas de policía para enfrentar únicamente las amenazas internas, confiando su seguridad exterior al culto al derecho internacional (Esquivel 2019). Esto se evidenció con la aplicación del modelo de alta policía.

Este modelo de alta policía aplicado por el Estado colombiano tuvo su origen posterior a la Revolución francesa, y se trató de un modelo de seguridad centralizado con servicios de inteligencia enfocado exclusivamente al ámbito interno (Esquivel 2019). Dicho modelo fue instaurado en Colombia a partir de la Independencia con el fin de perseguir a los conspiradores contra la República, entre otras amenazas (Esquivel 2019). Producto de este modelo fue la creación de la Policía Nacional, la cual surgió de la fusión de los serenos de Bogotá y los gendarmes de Cundinamarca (Esquivel 2019). 
Simultaneo a la utilización primigenia de los servicios de inteligencia en el ámbito interno, en el ámbito exterior el Estado no los implementó, sino que confió exclusivamente en las normas de derecho internacional. Esto se manifestó por medio de la "Policía de fronteras", que no fue algo más que un compendio de normas de derecho interno tendientes a castigar a quienes pretendieran atacar el territorio colombiano desde un Estado vecino. El Estado colombiano, lejos de implementar una verdadera vigilancia de las amenazas que pudieren provenir del exterior, se limitó a consagrar unas pocas normas que se pensaba evitarían cualquier agresión.

En 1911, debido a las continuas incursiones de fuerzas peruanas en el Caquetá, el gobierno destacó la primera sección de Gendarmería en dicha zona, la cual fue reemplazada por un destacamento del Ejército (Esquivel 2010). En esos mismos años se estaban desarrollando diferentes entidades administrativas para la vigilancia de fronteras; sin embargo, el Estado solo lograba tener presencia en dichas zonas cuando enviaba tropas del Ejército para atender emergencias.

A pesar del carácter evidente de las amenazas exteriores que tenía Colombia por esa época, sus dirigentes seguían confiando en la efectividad de los tratados firmados, por lo que no consideraron necesario monitorear dichas amenazas (Esquivel 2019). Por otra parte, coherente con la política de alta policía, se continuó fortaleciendo las fuerzas de policía a través de distintas misiones contratadas entre 1916 y 1936. Por consiguiente, la seguridad del Estado continuó enfocada únicamente en las amenazas internas de la nación.

El Ministerio de Relaciones Exteriores fue la entidad estatal que se encargó, en un primer momento, de advertir las posibles amenazas exteriores contra Colombia (Esquivel 2019). En esta etapa, el ministerio se encargó de recolectar la información pertinente de cada país a partir de los informes periódicos que debían enviar los cónsules dispuestos en cada uno. Si bien se recolectaba la información, no existía alguien que se encargara de sistematizar ni analizar dicha información, por lo que no se puede afirmar que este proceso de recolección por sí solo significara la existencia de un proceso de gestión del conocimiento.

La inexistencia de la inteligencia estratégica en Colombia tuvo su mayor expresión en la independencia de Panamá. Durante los años anteriores a este incidente Colombia permitió el establecimiento de personal francés, británico y estadounidense en su territorio, basándose en la buena fe al suponer que se trataba, únicamente, de misiones de carácter científico o comercial que, en realidad, "recogían datos precisos para el mejor despliegue de tropas y naves" (Esquivel 2019, 395). Esta falta de una inteligencia estratégica y, por ende, de una buena gestión del conocimiento, aunada a la excesiva confianza en el derecho internacional, derivó en que "la posterior independencia de Panamá no fue sorpresa para Gran Bretaña, Francia y EE. UU., pero sí para los colombianos" (Esquivel 2019, 395).

A pesar de todos estos antecedentes, es hasta mediados del siglo XX que se puede encontrar un primer hito hacia la construcción de un sistema de gestión del conocimiento que permitiese la consolidación de la inteligencia estratégica en Colombia. "La primera entidad encargada del servicio de inteligencia estatal en el país fue el Servicio de Inteligencia de Colombia (SIC) creado en 1953 por el General Gustavo Rojas Pinilla" (Méndez 2018, 9). Sin embargo, esta entidad también tuvo a su cargo funciones de apoyo a la justicia penal y disciplinaria, por lo que se puede concluir que "la función de inteligencia era abiertamente confundida con funciones de investigación criminal e incluso con investigación disciplinaria” (Romero 2016, 9). Es decir, aún no se consolidaba un organismo encargado exclusivamente de gestionar el conocimiento respecto a las amenazas externas del Estado. "No obstante, el SIC se constituyó como el primer organismo civil de inteligencia que era, además, directamente dependiente de la Presidencia de la República" (Esquivel 2019, 396).

Posteriormente, en 1960, se reemplazo el SIC por el Departamento Administrativo de Seguridad (DAS). Esta nueva entidad tenía tres funciones: ejercer como policía judicial, colaborar con el mantenimiento del orden público y llevar el registro de extranjeros (Esquivel 2019). El DAS 
fue la entidad que tuvo a su cargo la gestión de la información de inteligencia con la finalidad de la seguridad del Estado, entre otras funciones, hasta su disolución de 2011.

En el ámbito normativo, el presidente Samper creó en 1995, vía decreto, el Sistema Nacional de Inteligencia, el cual, entre sus objetivos se encontraban la unificación de las políticas de inteligencia, el fortalecimiento de la integración de las agencias de inteligencia, y el fortalecimiento de los procesos de gestión de la información (Montero 2017). De igual manera, se creó el Consejo Técnico Nacional de Inteligencia como un esfuerzo de articular los servicios de inteligencia de naturaleza civil y militar.

"Posteriormente bajo el gobierno del presidente Álvaro Uribe se propuso el primer ejercicio de una Ley de inteligencia" (Montero 2017, 143). Este proyecto, que se materializó en la Ley 1288 de 2009, tenía como propósito el fortalecimiento del marco legal de los organismos de inteligencia y contrainteligencia para que puedan cumplir de una manera adecuada con sus funciones. Sin embargo, esta ley fue declarada inexequible por la Corte Constitucional, por lo que se tuvo que reformular (Montero 2017). Tal reformulación llegaría en 2013 con la expedición de la Ley 1621 de 2013, la cual cumplía con el objetivo planteado en la ley anterior, al mismo tiempo que fijaba los límites de estas actividades.

Simultáneo a esto, en 2011, se fundó, en reemplazo del DAS, la Dirección Nacional de Inteligencia (DNI), que está encargada de la seguridad nacional gracias al desarrollo de actividades de inteligencia estratégica (Venegas, 2018). Sin embargo, el hecho de que las relaciones exteriores de Colombia sigan imbuidas en el culto al derecho internacional impide que las actividades de esta nueva agencia puedan ser consideradas como inteligencia estratégica (Esquivel 2019). A pesar de esto, Colombia, en la actualidad, cuenta con distintas instituciones cuya función se enfoca en propender por la seguridad nacional y el orden público a partir de actividades de gestión del conocimiento (Sierra 2010). Entre estas podrían encontrarse las dependencias de inteligencia de cada una de las Fuerzas Militares, de la Policía Nacional, y otras como la Unidad de Información y Análisis Financiero (UIAF) (Sierra 2010).

\section{ESCENARIOS DE AMENAZA QUE POSEE COLOMBIA EN LA ERA POS-COVID.19}

En un principio el concepto de seguridad sugiere "un estado o sensación que produce la percepción de ausencia de amenazas que coloque en riesgo la existencia, propiedad, intereses, valores o el particular modo de ser de quien percibe" (Saint-Pierre 2008, 59). En efecto, esta percepción tiene origen en la distinción de una amenaza que puede ser entendida como vulnerabilidad, peligro o la incapacidad e imposibilidad para identificarla y disminuir sus efectos; además, puede provenir, de una nación, pueblo, etnica, grupo e individuo (Saint-Pierre 2008).

De acuerdo con lo anterior, para propósito de este escrito, se tomará en cuenta el concepto de seguridad desde una perspectiva estatal. El concepto clásico de seguridad a nivel nacional explica que se tiene como objetivo evitar o rechazar amenazas militares y, correspondientemente, proteger militarmente de posibles agresores de los 3 principales elementos de un Estado: soberanía, independencia y territorialidad (Font y Ortega 2012). No obstante, en los años ochenta surgieron enfoques críticos frente a este concepto de seguridad, señalando que sólo se centraba en la seguridad del Estado y se olvidaba, por tanto, de los ciudadanos y otras fuentes de inseguridad a nivel internacional y nacional; tales como: económicas, políticas, sociales y me dioambientales (Font y Ortega 2012). El Estado ya no es el único actor a nivel internacional, aunque no fue hasta el fin de la guerra fría que se reforma el concepto de seguridad por uno con perspectiva multidimensional, que asume nuevas amenazas y contempla el fenómeno de la globalización.

Las nuevas amenazas y desafíos a los que se enfrentan los Estados son: terrorismo, delincuencia organizada transnacional, pobreza extrema y exclusión social, trata de personas, ataques de ciberseguridad, corrupción, tráfico ilícito de armas, desastres naturalez, VIH/SIDA, entre otros (Organización de Estados Americanos [OEA] 2003). En el caso de Colombia, se precisa 
que las amenazas a las que el país se enfrenta, principalmente, son: economías ilegales, minería ilegal, crimen cibernético, delincuencia organizada y narcotráfico (Cubides y Ramírez 2018) precisan; los cuáles se han facilitado por fenómenos como la globalización que se considera un proceso en el que las economías, los mercados, la comunicación y las personas adquieren una dimensión mundial, superando las barreras físicas y las acciones reguladoras de los Estados (Bravo 2015). No obstante, aunque se contemplen algunas amenazas considerando el contexto histórico, social, económico, político y cultural del país, como los mencionados con anterioridad, en algunos casos surgen otras amenazas que están sujetos al contexto global.

A partir del 27 de noviembre de 2019 el mundo se ha enfrentado a una enfermedad infecciosa (COVID-19) que tuvo origen en la ciudad de Wuhan, China y posteriormente se expandió en lo extenso de los territorios. En Colombia, el primer caso fue confirmado el 6 de marzo de 2020 por el Ministerio de Salud y Protección Social tras realizar las muestras y análisis correspondientes a una ciudadana procedente de Milán, Italia (Ministerio de Salud y Protección Social 2020). Así, considerando lo expuesto, una persona puede, principalmente, contraer el virus del COVID-19 por medio del contacto con otra persona que esté contagiada, a través de partículas que son eyectadas por la naríz o boca de quien está infectado cuando tose, estornuda o incluso habla, y son inhaladas por la otra persona no infectada (Organización Mundial de la Salud 2020). Sin embargo, también puede suceder si una persona expulsa esas partículas sobre algún objeto o superficie (barandas, mesas, pomos de puertas, entre otros) y la otra persona, luego de tocar esas superficies, toca su naríz, boca u ojos (Organización Mundial de la Salud 2020). Actualmente, debido al COVID-19 han fallecido miles de personas y se desataron crisis en un sinnúmero de aspectos.

Pese a que la llegada del virus se dio de manera más tardía en América Latina, sus estragos han sido igual de espeluznantes. El COVID-19 es un problema global, pero los gobiernos deben enfrentarlo, ante todo, de manera local, siendo así un estrés para los gobiernos, reto de liderazgo para los presidentes e inclusive un aspecto decisivo para elecciones. En Colombia la crisis del coronavirus arribó en medio de una gran inestabilidad sociopolítica que recién superaba las protestas masivas contre el gobierno llevadas a cabo en noviembre y diciembre de 2019. Además, se avistaban malas perspectivas económicas. Por tanto, es pertinente identificar los escenarios de amenaza que posee Colombia en la era pos-COVID-19 desde una perspectiva de seguridad multidimensional.

Los aspectos que se considerarán a continuación son: el económico-social, el político y el sanitario. En Colombia, el desempleo para el mes de septiembre de 2019 era del 10,1\% y para septiembre de 2020 es de 18,3\%, significando esto un aumento de 8,2 puntos porcentuales con respecto al año pasado (DANE 2020); la contracción del PIB nacional en Colombia se refleja en las pérdidas económicas que varían entre 4,6 billones de pesos y 59 billones, lo cual representaría alrededor de 0,5\% y 6,1\% del PIIB nacional Galvis-Aponte m2020); y, se afirma que el 70\% de las empresas están en riesgo de quiebra, puesto que se acogen a la Ley de Quiebra (Ley 1116 de 2016) que le permite a las empresas normalizar sus relaciones comerciales y crediticias (ANDI citada en Semana 2020). El impacto a nivel mundial que ha causado el COVID-19, se ve reflejado especialmente en el cierre parcial o total de las pequeñas y medianas empresas, cancelación de contratos de arrentamiento, vacaciones anticipadas, despidos masivos, contracción de la economía y licencias no remuneradas, las cuales se relacionan todas entre sí debido a que las empresas que no están en capacidad de cumplir con las nóminas y gastos fijos mensuales ya establecidos por la abrupta disminución de sus ingresos -ya sea por inactividad, baja producción o ambos- y terminan estando al mínimo de la insolvencia y una muy poca capacidad de pago a largo plazo, lo cual termina afectando indiscriminadamente a los empleados y consecuentemente al PIB nacional (Cuncanchon 2020).

Asimismo, se fomenta la desigualdad y pobreza en Colombia, puesto que hogares con niveles de ingreso y consumo superiores -por poco- a las líneas de pobreza están altamente 
expuestos al ciclo económico que se ha visto bastante afectado. El ingreso mediano mensual de las familias se desplazaría hacia niveles más cercados a la línea de pobreza, dado como resultado un incremento de cerca de 15 puntos porcentuales adicionales de pobreza, alrededor de 7,3 billones más que en 2019 (Universidad de los Andes 2020).

Del mismo modo, el ministro de Salud y Protección Social, Fernando Ruíz Gómez, afirmó que la pandemia del COVID-19 ha puesto en evidencia las debilidades y fortalezas del sistema, entre los cuales está el desarrollo de mucho de lo planteado y expuesto en la Ley Estatutaria de Salud (Ministerio de Salud y Protección Social 2020). También, las reacciones inmediatas y las decisiones que se basan en salud pública deben mejorar, pues la precariedad de los centros médicos a nivel nacional e internacional también han quedado al descubierto, la falta de implementos médicos, medicamentos, personal de la salud y la escasa capacidad en los centros hospitalarios, en algunos casos, condiciosados incluso por condiciones climáticas (Ministerio de Salud y Protección Social 2020).

Los escenarios de amenaza que posee Colombia en la era pos-COVID-19 se reflejan principalmente, según lo expuesto con anterioridad, en el aspecto económico-social, político y sanitario, aunque son variados. Por tanto, los Estados deben diseñar y desarrollar estrategias que les permitan enfrentar tales amenazas.

\section{PAPEL QUE POSEE LA GESTIÓN DE CONOCIMIENTO EN LOS PROCESOS DE INTELIGENCIA ESTRATÉGICA EN LA ERA POS-COVID 19 EN COLOMBIA}

La gestión del conocimiento, también a menudo denominada administración del conocimiento es definida de la siguiente manera:

El conjunto de procesos por los cuales una empresa u organización recoge, analiza, asequibiliza y comparte su conocimiento entre todos sus miembros con el objetivo de valuar los recursos intelectuales del colectivo en beneficio de la empresa, la organización, el individuo y la sociedad (Fresno Chávez 2018, 40).

Esta definición implica, entonces, que la gestión del conocimiento se refiere a todos los procedimientos de los que es objeto la información dentro de cualquier organización, sea pública o privada. Estos procedimientos no se refieren únicamente al manejo que se le de a la información que se posee, sino que comprende también los procesos por medio de los cuales dicha información es obtenida por parte de la organización.

Este concepto de gestión del conocimiento está estrechamente ligado al de inteligencia. Por inteligencia se pueden aceptar tres concepciones: información utilizada para la formulación y la implementación de las políticas; actividad de colección y análisis de dicha información y; organizaciones burocratizadas que se encargan de desarrollar tal actividad en un país (Cárcamo 2017).

De acuerdo con lo anterior, el término inteligencia implica necesariamente gestión del conocimiento. Las distintas concepciones del término establecen la gestión del conocimiento como el fundamento de la inteligencia (Cárcamo 2017). Por ejemplo, la inteligencia entendida como “información relevante para la formulación y la implementación de políticas" (Cárcamo 2017, 71), la establece como el objeto material sobre el que se desarrollan los procesos de gestión del conocimiento. La segunda concepción de inteligencia la trata como sinónimo de gestión del conocimiento, al referirse a esta como las actividades de recolección y procesamiento de la información. Y la última concepción se refiere a esta como los actores que están a cargo de la gestión del conocimiento.

Esta sinergia entre gestión del conocimiento e inteligencia nos permite tratarlas como sinónimos, aunque, como se ha mencionado en párrafos anteriores, la palabra inteligencia aborde 
una mayor amplitud de significados que los procesos de gestión del conocimiento. Sin embargo, también existe el concepto de inteligencia estratégica como una manera de otorgarle sentido o una finalidad a la gestión del conocimiento.

La Inteligencia Estratégica como la conocemos, hoy en día, es el análisis producido en un proceso separado del usado para desarrollar una política. Es la combinación de diferentes fuentes de información para lograr un análisis que va mucho más allá de una simple descripción de un despliegue militar o un evento político; se amplía en áreas como el análisis del poder en todas sus manifestaciones, las comunicaciones, el espacio cibernético, y la tecnología en un mundo globalizado e interdependiente (Saavedra 2015, 77-78).

Es decir, la inteligencia estratégica se refiere al proceso de gestión del conocimiento desarrollado a partir de múltiples fuentes de información, con la finalidad de obtener un análisis más completo y preciso de una situación o problemática específica. En términos más específicos, es posible definir inteligencia estratégica "como el intento de los dirigentes por conocer las amenazas potenciales e inminentes a nivel nacional o internacional y sacar ventaja de ellas" (Esquivel 2019, 380). Tales amenazas pueden ser tanto de carácter interno como de carácter externo (Esquivel 2019).

Esta última definición del concepto de inteligencia estratégica aportada demuestra la relevancia de estos procesos para la seguridad y la estabilidad de cualquier Estado-nación en cualquier contexto espacial y temporal (Esquivel 2019). La inteligencia estratégica no es algo diferente que ese proceso de gestión del conocimiento mediante el cual es posible determinar los factores que amenazan o que se presentan como oportunidades para un Estado y una población en un contexto específico. Por consiguiente, la importancia de la inteligencia estratégica reposa en la relevancia de esa información que se obtiene y se procesa por medio de esta.

La posesión de la información precisa es fundamental para la toma de buenas decisiones. De acuerdo con Ferratto, "cuanto más sepa un decisor acerca del problema con el cual debe lidiar, tanto más probable será que adopte decisiones políticamente inteligentes y aplicables" (Ferratto 2014, 62-63). Es decir, los procesos de gestión del conocimiento propios de la inteligencia estratégica reducen el margen de error por parte de los tomadores de decisiones, pues les otorga una visión más amplia frente a las problemáticas a las que se están enfrentando.

En este mismo sentido, la carencia de información o, la falta de procesamiento de esta, aumentan la vulnerabilidad de cualquier organización al someterla a amenazas desconocidas. Además, en virtud de tal desconocimiento, no se cuenta con los medios adecuados para responder a estas en el momento en que por fin son detectadas. Por citar un ejemplo, se adjudican a la falta de información y a la no integración de los datos disponibles debido a un erróneo procesamiento, una de las causas de los atentados sucedidos el 11 de septiembre de 2001 en Washington y Nueva York (Esteban y Navarro 2002).

El anterior ejemplo ilustra el carácter esencial de la inteligencia estratégica para la estabilidad de un Estado y de una población. Sin una inteligencia estratégica, cualquier sociedad en el mundo es vulnerable a cualquier amenaza existente o en gestación, porque las amenazas no son estáticas, sino que van apareciendo, consolidándose y desapareciendo con el paso del tiempo, de manera que se requiere de una gestión del conocimiento permanente por parte de los servicios de inteligencia. En otras palabras, las amenazas y los riesgos cambian cada día, surgiendo nuevos fenómenos, grupos e interrelaciones, por lo que los mapas de conocimiento deben reflejar adecuadamente ese cambio, con el fin de conciliar la información disponible con las necesidades más recientes (Blanco,2015). Una prueba de la mutabilidad de las amenazas es que, en 2015, se identificaban como grandes amenazas para la seguridad internacional la tensión en Ucrania y el grupo terrorista "Estado Islámico; amenazas que, en 2020, están totalmente desactivadas o al 
menos debilitadas (Blanco 2015). Por el contrario, el virus que produce el COVID-19, la gran amenaza del año 2020 surgió finalizando el año 2019.

La emergencia por la pandemia del COVID-19 es el ejemplo más reciente de la necesidad imperante de la gestión del conocimiento en la era de la globalización. Siguiendo a Saavedra, "las naciones del mundo están actualmente más integradas de lo que estaban hace pocas décadas" (Saavedra 2015, 79), lo cual las hace más vulnerables a padecer en bloque los efectos de cualquier tipo de amenaza surgida en cualquier lugar del globo. En el caso de la pandemia del nuevo coronavirus, el mundo ha sido testigo de cómo una amenaza surgida en China, a los pocos meses consiguió paralizar el mundo entero.

Es debido a esta rapidez con la que se expanden las amenazas que se requiere que cada Estado cuente con una inteligencia estratégica eficiente. Los procesos de gestión del conocimiento deben estar preparados para detectar amenazas cuya expansión es cada vez más veloz en virtud de la globalización. De igual manera, la amenaza del COVID-19 ha revelado la necesidad de ampliar el espectro de las amenazas a ser tenidas en cuenta por los organismos de inteligencia; es decir, trascender hacia una inteligencia para la seguridad y la defensa.

Este último punto supone una ampliación del panorama de lo que se percibe como amenaza por parte de los Estados contemporáneos. Autores advierten la naturaleza no convencional de las amenazas del siglo XXI, que van desde la proliferación de las armas de destrucción masiva hasta el ciberterrorismo y el terrorismo bacteriológico (Esteban y Navarro 2002). Por ende, es indispensable pasar de una inteligencia militar, orientada a la vigilancia de un enemigo potencial o real o a la preparación de acciones bélicas, por una inteligencia para la seguridad y la defensa, referente a la protección de los intereses nacionales y la estabilidad de las instituciones del Estado (Esteban y Navarro 2002).

La sección anterior del presente artículo demostró que las amenazas contra el Estado son de naturalezas muy diversas. Las nuevas amenazas trascienden el carácter estrictamente militar de las amenazas convencionales y, en cambio, abarcan toda una gama de desafíos a nivel económico, político y social. En el caso del COVID-19, por ejemplo, las mayores consecuencias, además de la pérdida de tantas vidas humanas, han sido de carácter económico debido a las parálisis económicas a las que se han sometido los distintos Estados en algunos momentos.

Por estas razones, contar con una inteligencia estratégica de carácter multidimensional, es decir, que recopile y procese información no solo del ámbito militar sino de otros campos como el económico, el social, o de salud, es indispensable de cara a la era pos-COVID-19. Esto implica que se requiere de una gestión del conocimiento realmente eficiente, que sea capaz de recopilar, analizar y sintetizar información proveniente de las más diversas fuentes y que abarque distintos campos, con el fin de que los tomadores de decisiones tengan un panorama más claro y completo de las amenazas a las que se enfrentan y poder así ejecutar las políticas públicas más adecuadas. Ante la rapidez y la diversidad de efectos de las nuevas amenazas se debe responder con una gestión del conocimiento eficiente y multidimensional.

La gestión del conocimiento es el corazón de la inteligencia estratégica, pues se refiere a todos los procesos enmarcados en el concepto de inteligencia, a saber, aquellos que recopilan y procesan la información con la que se cuenta. "La inteligencia no se construye mediante una suma de datos, sino a partir de un determinado modo de analizar éstos sobre hechos" (Esteban y Navarro 2002, 274). Por tal razón, ante la diversidad de las amenazas presentes en la era pos-COVID-19, es esencial contar con los procesos óptimos y completos de análisis de información, de manera que brinden una perspectiva más amplia y universal que el aspecto estrictamente militar. Este es el desafío de la gestión del conocimiento dentro de los procesos de inteligencia estratégica en la era pos-COVID-19.

De esta manera, es posible concluir que la gestión del conocimiento aporta mucho a los procesos de inteligencia estratégica y será sumamente útil en la era pos-COVID-19, puesto que permite que se realice una verdadera comprensión de la información obtenida y se estudie su 
aplicabilidad en los escenarios de crisis. Una respuesta más rápida y eficiente puede lograr que en otra ocasión se pierdan un número mucho menos de víctimas y el impacto del fenómeno sea menor y controlado. Las experiencias pasadas y los escenarios similares permiten que, mediante la gestión del conocimiento, haya un proceso de reaprendizaje y reflexión. Además, estos procesos permiten que los Estados identifiquen y prevean las amenazas y crisis antes de que se manifiesten puesto que, al ser éstas de diversa índole, como el COVID-19, por lo que se necesita recopilar, sistematizar y procesar información de cada una de ellas. El ámbito militar, aunque importante, no es el único relevante a nivel internacional y nacional para proteger y garantizar la seguridad de los Estados; de hecho, la enfermedad viral COVID-19 lo demostró, debido a que es una amenaza que ningún Estado-Nación consideró y por tanto no tuvo una preparación previa, era un campo muy desconocido para tu accionar. Es importante, por ello, que los Estados realicen estos procesos que permitan atender las diversas amenazas, que incluso estén preparados para lo impensable.

\section{REFERENCIAS}

ARDILA CASTRO, Carlos Alberto., Jiménez Reina, Jonnathan.., \& Acosta Guzmán, Henry Mauricio. 2019. La Cultura de Inteligencia Estratégica como factores para la construcción de Estado: Caso colombiano. En Espaliú Berdud, Carlos (Ed.). «El conflicto y su situación actual: del terrorismo a la Amenaza Híbrida». Pamplona: Cizur Menor: Civitas Thomson Reuters. doi: https://doi.org/10.32029/2605-4655.02.24.2019

ARDILA CASTRO, Carlos Alberto., Jiménez Reina, Jonnathan.., \& Cubides Cárdenas, Jaime. 2018. La Inteligencia Estratégica en el Sistema Internacional. En Gines Alegría, César Augusto y Delgado Morán, Juan José. (Eds.). «Conflictos y Diplomacia, Desarrollo y Paz, Globalización y Medio Ambiente». Pamplona: Thomson Reuters Aranzadi.

BALLESTEROS MARTIN, Miguel Ángel. 2016. En búsqueda de una estrategia de seguridad nacional. España: Ministerio de Defensa de España. https://bit.ly/376nw70

BLANCO NAVARRO, José María. 2015. «Gestión del conocimiento y cultura de seguridad». Cuadernos de la guardia civil: Revista de seguridad pública 1: $48-71$. https://bit.ly/37ayRmO

Bravo Acevedo, Guillermo. 2015. «Las migraciones internacionales y la seguridad multidimensional en tiempos de la globalización». Diálogo Andino 48. doi:

http://dx.doi.org/10.4067/S0719-26812015000300013

CÁRCAMO HUN, Rodrigo. 2017. «Chile: consideraciones sobre el control civil de la inteligencia militar». URVIO - Revista Latinoamericana de Seguridad Ciudadana 21: 70-86. https://bit.ly/3739VgN

CUBIDES CÁRDENAS, Jaime y Ramírez Benitez, Erika Paola. 2018. Una mirada a la construcción de paz desde la seguridad humana en Colombia en el escenario de posconflicto. En Convergencia de conceptos: Enfoques sinérgicos en relación a las amenazas a la seguridad del Estado colombiano, ed. por Coronel Carlos Ardila y Jonnathan Jiménez, 141-172). Escuela Superior de Guerra.

CUNCANCHON BARBOSA, Gisel Carolina. 2020. El impacto negativo del COVID-19 sobre el empleo en Colombia. Tesis de especialización. Universidad Católica de Colombia. https://bit.ly/2Kuir0E 
DANE. 2020. «Gran encuesta integrada de hogares (GEIH) Mercado laboral». Acceso el 19 de noviembre. https://bit.ly/39cT2Tq

ESQUIVEL TRIANA, Ricardo. 2010. «Neutralidad y orden: política exterior y militar en Colombia, 1886-1918». Bogotá: Universidad Javeriana.

ESQUIVEL TRIANA, Ricardo. 2019. «Método histórico e inteligencia estratégica en Colombia, 1888-2001». Revista Científica General José María Córdova 17(26): 379-400. doi: https://doi.org/10.21830/19006586.388.

ESTEBAN NAVARRO, Miguel Ángel, \& Navarro Bonilla, Diego. 2002. «Gestión del conocimiento y servicios de inteligencia: la dimensión estratégica de la información». $E l$ profesional de la información, 12(4): 269-281. https://bit.ly/39hPQ9r

FRESNO CHÁVEZ, Caridad. 2018. «¿Qué es la gestión del conocimiento?». El Cid Editor. https://bit.ly/39aW6j3

FERRATTO, Andrés. 2014. «Crimen organizado e inteligencia estratégica: desafíos para el siglo XXI». URVIO - Revista Latinoamericana de Seguridad Ciudadana 15: 55-70. doi: https://doi.org/10.17141/urvio.15.2014.1587

FONT, Tica Y Ortega, Pere. 2012. «Seguridad nacional, seguridad multidimensional, seguridad humana». Papeles 119: 161 - 172. https://bit.ly/3fvjlFD

GALVIS-APONTE, Luis Armando, 2020. Impacto económico regional del COVID-19 en Colombia: un análisis insumo-producto. doi: https://doi.org/10.32468/dtseru.288

MÉNDEZ CHAUX, Álvaro Esteban. «Análisis de la política pública de inteligencia estratégica en Colombia». Tesis de pregrado. Universidad de los Andes, 2018. https://bit.ly/360ZhIk

MINISTERIO DE SALUD Y PROTECCIÓN SOCIAL. 2020. «Colombia confirma su primer caso de COVID-19». Acceso el 15 de noviembre. https://bit.ly/378eJRY

MONTERO MONCADA, Luis Alexander. 2017. «El rol de la inteligencia y las operaciones para los desafíos estratégicos». En Los ejércitos y el sistema internacional contemporáneo: nuevas amenazas, tendencias y desafios, 117-150. Escuela Superior de Guerra. https://bit.ly/35XzPmT

ORGANIZACIÓN DE LOS ESTADOS AMERICANOS [OEA]. 2003. Conferencia especial sobre seguridad. Declaración sobre Seguridad en las Américas. Acceso el 15 de noviembre. https://bit.ly/39aUu8Y

ORGANIZACIÓN MUNDIAL DE LA SALUD. 2020. «Preguntas y respuestas sobre la enfermedad por coronavirus (COVID-19)». https://bit.ly/39dmUiS

ORGANIZACION MUNDIAL DE LA SALUD. 2020. «WHO Coronavirus Disease (COVID19) Dashboard». Acceso el 15 de noviembre. https://bit.ly/3meTrsx

SAAVEDRA, Boris. 2015. «Inteligencia Estratégica en un mundo globalizado en Latinoamérica: Retos y desafíos en el siglo XXI». Revista Policía Y Seguridad Pública 5(2): 75-105. doi: https://doi.org/10.5377/rpsp.v5i2.2326 
ROMERO RÍOS, Herbert Harbey. «La inteligencia en Colombia: "De la oscuridad a la institucionalidad"». Tesis de especialización. Universidad Militar Nueva Granada, 2016. https://bit.ly/3pWA9dA

SAINT-PIERRE, Héctor. 2008. «Seguridad y Defensa». Atlas comparativo de la Defensa en América Latina, 1: 59 - 62. https://bit.ly/2KwAGm5

SEMANA. 2020. «Economía: "Hay riesgo de una crisis": ANDI». Acceso el 14 de noviembre. https://bit.ly/39deVSz

SIERRA PINILLA, Adriana Astrid. 2010. «La inteligencia estatal en Colombia: su aplicación e implicaciones frente al derecho a al intimidad y libertad personal». Iter ad veritatem, 8: 157-172. https://bit.ly/3fshjpV

VENEGAS, Álvaro José. 2018. «En busca de inteligencia estratégica: cuatro factores para el nacimiento y evolución de una inteligencia civil colombiana». Ciencia Política 13(26): 287-318. doi: https://doi.org/10.15446/cp.v13n26.71938 